\title{
As ações culturais do Departamento de Cultura da cidade de São Paulo através dos Parques Infantis
}

\section{The cultural activities of the Departamento of Culture of São Paulo through Playgrounds}

Lucas Garcia*

lgarcia@id.uff.br

Resumo

O presente trabalho tem com objetivo a discussão da gestão dos Parques Infantis pelo Departamento de Cultura da cidade de São Paulo, na década de 1930. De certo, influenciados pelo movimento modernista, os gestores aplicaram novos métodos às atividades dos parques que atendiam crianças de 3 a 12 anos de idade, filhas de operários e trabalhadores de fábricas. Dirigido por Mário de Andrade, o departamento obteve em poucos anos ótimos resultados e se tornou referência em alguns países europeus, inaugurando assim as políticas culturais no Brasil.

Palavra-Chave: Parque Infantil, Departamento de Cultura, Mário de Andrade, Política Cultural

\begin{abstract}
The present work is aiming to discuss the management of playgrounds by the Department of Culture of the city of São Paulo, in the 1930s. From right, influenced by the modernist movement managers have applied new methods to the activities of Parks that served children from 3 to 12 years old, daughters of laborers and factory workers. Directed by Mario de Andrade's Department obtained excellent results in a few years and became a reference in some European countries, thus inaugurating the cultural politics in Brazil.
\end{abstract}

Key word: Playground, Departament of Culture, Mário de Andrade, Cultural Politics

* Mestrando do Programa de Pós-Graduação em Cultura e Territorialidades - Universidade Federal Fluminense (UFF) 
Artigos

\begin{abstract}
"São Paulo quer-se bonita e higiênica para que o viajante não venha mais encontrar nela, apenas sapo, gripe e solidão. Os grotões transformaram-se em jardins cortados a meio pelas avenidas e pela sombra dos viadutos. Não há mais sapo. Nos jardins encontrarei recintos fechados com instrutoras, dentistas, educadoras sanitárias dentro. São os Parques Infantis onde as crianças proletárias se socializam aprendendo nos brinquedos o cooperativismo e a consciência social." (Mário de Andrade - 1935)
\end{abstract}

Pretende-se com esse estudo explanar as práticas dos processos de gestão envolvidas, pontualmente, no projeto dos Parques Infantis administrado pelo Departamento de Cultura da cidade de São Paulo, a partir de 1935, dirigido por Mário de Andrade, ligados a Divisão de Educação e Recreação. Um projeto- piloto e moderno de gestão pública para aquela época, no recorte espacial paulistano.

Apresentamos aqui um pouco deste projeto, inserido no organograma da administração pública, os processos envolvidos e os espaços selecionados para receber o projeto, além é claro da equipe que integrava as atividades, seja direta ou indiretamente. Em especial, trabalhamos com a imagem do diretor do departamento, Mário de Andrade, no que diz respeito à síntese dos parques e sua evolução para então analisarmos as políticas públicas iniciadas no Brasil. Relacionaremos as proposições referentes a alguns pensadores e os acontecimentos políticos iniciados na cidade de São Paulo, no período de 1935, na gestão de Fabio Prado na prefeitura do município.

É importante ressaltar que o Brasil ainda não havia vivenciado ações contínuas e sistemáticas que representariam as políticas públicas culturais. Portanto, a gestão que se iniciava na década de 1930, ao mesmo tempo em que era inovadora, não encontrava referências próximas, no que tange o âmbito nacional. Como afirma Canclini.

"Los estúdios recientes tiendem a incluir este concepto al conjunto de intervenciones realizadas por el estado, las intituiciones civiles y los grupos comunitários organizados a fin de orientar el desarrollo simbólico, satisfacer las necessidades culturales de la poblacións y obtener consenso para um tipo de ordem o transformacion social. Pero esta manera de caracterizar el âmbito de las políticas culturales necesita ser ampliada teniendo em cuenta el caráter transnacional de los procesos simbólicos y materiales em la actualidad.” (BARBALHO, 2007, p.13)

Podemos notar uma amplitude no conceito da política cultural em diferença com ações pontuais no Brasil Império de Dom Pedro II, um mecenas. O interesse pessoal do imperador não responde a questões e definições que nos apresenta Rubim referentes as políticas culturais: "intervenções conjuntas e sistemáticas; atores coletivos e metas" (BARBALHO, 2007, p.14). Ele trabalha com a ideia de que no país existirá uma "triste tradição" na qual se encontra um perfil autoritário e elitista, o que influenciou diretamente as tardias políticas públicas voltadas à cultura. Vai além e enumera algumas justificativas pelas quais as políticas culturais brasileiras se iniciam com o Departamento de Cultura, na liderança de Mário de Andrade, em uma "definição ampla de cultura", patrimônio assumido além do tangível, independentemente de classes, "cultura tão vital quanto o pão" e acolhendo a cultura popular (Idem p.p. 15). Embora em defesa deste momento, de inauguração tardia das políticas, Rubim acrescenta uma crítica ao departamento, que com as exposições feitas adiante trarão um pensamento não tão pessimista:

"Dentre outras críticas ao seu projeto, cabe destacar: uma certa visão iluminista de imposição da cultura de elite e a desatenção com o tema do analfabetismo em uma sociedade tão excludente com a brasileira, em especial nos anos 30." (loc. cit)

De fato, o momento pelo qual passava o Brasil e a cidade de São Paulo é de imposição da cultura de uma elite intelectual, mas levemos em consideração os Parques Infantis e sua recepção às crianças que viviam no município crescente, com péssimas condições de moradia, insalubridade, acesso a hospitais, educação e cultura. Temos, a partir dessa afirmação de Barbalho, duas leituras a respeito do projeto piloto implantado pelo Departamento de Cultura do município.

Os Parques Infantis trarão boas perspectivas às crianças (mesmo que por pouco tempo) que das atividades participavam. Um perfil de meninos e meninas descuidados e de fato excluídos, até então, das práticas da governança. Agora imaginemos o interior do Brasil da época, se uma das maiores cidades do país presenciava esta realidade. Euclides da Cunha, com requinte e delicadeza, expõe a problemática de um sertão 
descuidado que sofre além das condições naturais, também pela falta de atenção da gestão pública (CUNHA, 1975).

Nos parques, a saúde foi considerada fundamental, mas permaneceu ao lado da educação e da cultura. Os primeiros levantamentos feitos pelo DeCult ${ }^{1}$ mostraram que a prioridade inicial deveria ser o estado físico das crianças, que não era muito animador. Esses fatos trazem consistência para desenvolvermos a proposta inicial, o projeto dos Parques Infantis gerido por uma política pública de cultura e educação.

A ideia uma instituição que estaria diretamente voltada à produção cultural, artística e educativa já havia sido semeada, antes mesmo da política do Café com Leite ter fim em 1930, em São Paulo por um grupo de intelectuais $^{2}$ que se reuniam semanalmente para discutir política e atualidades entre 1926 e 1931 (DUARTE, 1985, p.49). Nasceu assim o projeto do Instituto Paulista de Cultura, batizado naquelas reuniões, brindando os sonhos culturais com vinhos estrangeiros. Alguns anos depois, o chamariam de Departamento de Cultura da municipalidade de São Paulo.

Mário de Andrade chegou como indicação para a direção do Departamento de Cultura por meio do amigo Paulo Duarte, que trabalhava com Fabio Prado, prefeito de São Paulo desde 1934. Quando o projeto do departamento foi apresentado, a nomeação de Mário foi aprovada (Idem p.p.52). Ele dirigiria no total cinco divisões: Expansão Cultural, Bibliotecas, Educação e Recreio, Documentação Histórica e Social, Turismo e Divertimento Públicos. Teria a grande responsabilidade de trazer questões relacionadas à formação do brasileiro, já que a cidade crescia desde a virada do século e não existiam planos de educação e cultura sistematizados. Livros, discos, folclore e parques. Com esses equipamentos, propuseram uma mudança. Modernizar São Paulo não só na estrutura física, mas também na formação intelectual das pessoas que ali se estabeleceram. O novo conceito de cultura atribuído pela equipe do recém-criado DeCult semearia relações entre a cultura e o poder. Não podemos deixar as ações articuladas pelo departamento como meras ações sociais. A começar dos intelectuais que ocupariam os importantes cargos das novas políticas culturais paulista e brasileira.

Assim, a Divisão de Educação e Recreio possuía duas Seções: a de Parques Infantis e a de Estádio, Campos de Atletismo e Piscinas, embora essa divisão trabalhasse diretamente com a Divisão de Documentação Histórica e Social, que cumpria o papel de pesquisas e análises sociais dos parques. O projeto dos Parques Infantis foi criado na gestão $(1930$ - 1931) do prefeito Anhaia Melo, mas a ideia do projeto não foi desenvolvida e a nova gestão, anos mais tarde, por meio do DeCult, acreditou que seria um ótimo potencial a ser desenvolvido, e o fez. Os parques atendiam crianças de 3 a 12 anos de idade e funcionavam em um horário integral de 7 h30 às 18 horas, era um complemento à educação formal e deveriam ser instalados preferencialmente em bairros populares, perto de colégios, fábricas e habitações coletivas ${ }^{3}$. Nos parques, não havia a divisão de classes por idade, logo crianças de idades diferentes interagiam entre si. Com intuito de atender a necessidade das crianças, filhas de trabalhadores e operários, na formação educacional e cultural das mesmas. Muitas vezes eram filhas de estrangeiros e da nova classe operária que havia se instalado na cidade de São Paulo4.

Como afirma Paulo Duarte, os parques destinavam-se:

\footnotetext{
“(...) essencialmente a colaborar na obra da preservação, previsão social e de educação das crianças. Dentro deles, seriam dirigidos e acompanhados a prática e o desenvolvimento de brinquedos e diversões. Para tudo isso, em cada parque haveria tantos educadores sanitários, instrutores quanto reclamados pelo serviço. Com a colaboração dos institutos educativos, nele seria promovido um inquérito permanente de pesquisas psicológicas, folclóricas e outras, recolhendo as tradições de costumes, superstições, advinhas parlendas, estórias, canções, brinquedos etc..” (DUARTE, 1985, p. 81)
}

Devidamente exposto, os Parques Infantis foram pensados para muito além de um tempo ocioso na vida das crianças da cidade de São Paulo, em especial áreas que necessitavam de mais atenção referentes

\footnotetext{
1 Departamento de Cultura

2 André Dreyfus, Antônio de Alcantara Machado, Tácito de Almeida, Antonio Couto Barros, Paulo Duarte, Mário de Andrade entre outros.

3 Logo depois o horário noturno, de 18 h30 às 22 horas, seria incluída na programação, destinando-se aos adolescentes.

4 Italianos, alemães, sírios, libaneses, japoneses etc.
} 
Artigos

ao desenvolvimento social, da metrópole, apontadas pelos políticos. As experiências iniciais estarreceram os gestores de tal forma que foi instituída com urgência a implantação diária de merenda, para que as crianças pudessem desfrutar de uma alimentação saudável e gratuita. A iniciativa foi defendida depois de um levantamento, no qual se revelava que $60 \%$ das crianças que frequentavam as instalações do projeto eram desnutridas e passavam fome e 80\% careciam de atendimento médico (DUARTE 1985, p. 84). Na primeira experiência dos parques, inicialmente, não existia uma frequência, nem mesmo uma matrícula de crianças que participavam das atividades. Com o crescimento do projeto e o aumento na demanda, obedeceram à necessidade de criar uma inscrição e estabelecer um formulário de matrícula.

As pesquisas e os levantamentos estatísticos inovadores para a capital paulista seguiam os modelos americanos implantados em 1934 (SANDRONI, 1988). Com esses dados, assustadores, coletados , foram distribuídos lanches ${ }^{5}$ às 400 crianças que integravam as atividades do primeiro parque, Pedro II.

Além de alimentação gratuita e atenção médica (que incluía atendimento com nutricionista, psicológico, dentista, vacinação e clínico geral), as crianças ainda teriam atividades diárias nos parques com instrutores auxiliando-os nas práticas culturais e desportivas como: teatro, escultura, dança, brincadeiras ao ar livre, além do incentivo que recebiam para criar e desenvolver desenhos com uma estrutura adequada à produção, cumprindo o objetivo de trabalhar a mente e o corpo. Educadoras sanitárias auxiliavam as crianças na higiene alimentar, nos cuidados básicos que deveriam ter no âmbito doméstico familiar, no cuidado com a vestimenta, com o banho e possíveis doenças que poderiam ser combatidas com a prática diária de higiene básica. Os desenhos eram incentivados pelos educadores e instrutores, com o material necessário para as crianças realizarem as práticas propostas. Neles, existiriam legendas do que as crianças haviam elaborado seu nome, nacionalidade, o pai e da mãe, idade e cor. A partir dessa coleção de desenhos infantis, podemos potencializar a figura do multifacetado Mário de Andrade, que diversificadas tarefas explorou, entre elas: escritor, musicólogo, folclorista, crítico, entre outras, é importante destacar que os estudos realizados por ele muito influenciaram as novas coordenadas das práticas culturais não só paulista, mas também brasileira em nível do Serviço do Patrimônio Histórico e Artístico Nacional (SPHAN) que ele auxiliou a criação. A cultura na política recém-chegada era o resultado de anos de estudo e pesquisas em viagens e coletas pelo Brasil adentro.

Tendo em vista a grade de programação dos parques e as necessidades das crianças, surgiu um cuidado em conhecê-las, independentemente da localização dos parques.

Apropriados pelo poder público em um momento de busca pela representação nacional e mudanças no progresso estrutural, foi a hora adequada que os representantes públicos abraçaram os intelectuais. Obviamente, existia uma estratégia política planejada ao inserir no âmbito das políticas públicas pessoas das áreas da literatura e das artes. Os intelectuais serão novas peças do “jogo de xadrez" e terão função basicamente de mediar as ações políticas entre os representantes e a população que, apresentada anteriormente, era na grande maioria sem estudos e analfabeta. Uma das ações do Departamento de Cultura, além é claro dos Parques Infantis foi a implantação da gratuidade no Teatro Municipal de São Paulo defendida e acionada por Mário. Embora muito criticada, a ação foi um sucesso: "Pela primeira vez, o Teatro Municipal abriu as portas aos trabalhadores - "com grande inquietação dos meios grã-finos", que temiam depredações; mas resultou uma surpresa sensacional: não houve estrago nenhum" (Idem, pp.48). A elite paulista, do café, "dominava" as práticas artístico/culturais do Brasil que era do café e também do leite. Vivenciavam e investiam em uma arte totalmente influenciada pela arte europeia à qual o grupo de modernistas se opunha e defendiam o Brasil sem muitas influências estrangeiras, como no caso de Aleijadinho.

Desta forma, Jean Marie nos apresenta, em seus estudos relacionados ao rei da França Luiz XIV. "A monarquia impôs sua ordem aos feudais apoiando-se num grupo de letrados que ela formou e cuja importância aumentou com a do Estado." (MARIE, 1993, pp. 113). No Brasil, a partir da década de 1930, irão compor o Ministério os seguintes intelectuais: Manuel Bandeira, Carlos Drumond, Mário de Andrade, Graça Aranha, Rodrigo Melo Franco, Francisco Campos, Gustavo Capanema, Gustavo Barroso, entre tantos outros, participaram efetivamente dos debates políticos auxiliando o governo nas decisões relativas a arte, cultura e educação, que eram vinculadas ao antigo Ministério de Saúde e Educação, chefiado a partir de 1934, por Gustavo Capanema. No DeCult, a equipe era multidisciplinar e atendia às necessidades de cada divisão, especialistas no tema e estudiosos das áreas.

5160 litros de leite, 80 quilos de pão e sopa. 
O Brasil passa por um período de procura, de busca pela nacionalidade, por uma identidade que representasse seu povo, questões apontadas e trazidas fundamentalmente pelo Movimento Modernista de 1922. Os intelectuais trarão figuras específicas para a representação nacional, o mestiço, o mulato serão o grande diferencial do Brasil; serão explorados e analisados. Aleijadinho, Padre Jesuino do Monte Carmelo, Mestre Ataide e outros artistas serão apontados como peças importantes no que diz respeito a um aspecto de um Brasil até então não descoberto, interiorano, inquieto de características "puras" distante das propostas europeias, esses trazidos e explorados por Andrade no decorrer de seus estudos. Dentro das atividades aplicadas e inseridas nos Parques Infantis estarão presentes programas que exploram o folclore nacional (das práticas coletadas pelos intelectuais). Abraçando o Brasil, e uma construção cultural em que imigrantes chegavam de "mala e cuia" no porto de Santos. Os mulatos se tornam "geniais", o segredo e a graça do Brasil é a diferença, e a mestiçagem naturalmente assume esse posto, pelas obras de Gilberto Freyre, Sergio Buarque de Holanda e também Mário de Andrade. Dessa forma, nos apresenta Rubim: "A política cultural implantada valorizava o nacionalismo, a brasilidade, a harmonia entre as classes sociais, o trabalho e o caráter mestiço do povo brasileiro.” (BARBALHO, 2007, pp. 16). Momento decisivo.

Os Parques Infantis foram bem-sucedidos e, em três anos, já colhiam frutos do primeiro projeto instituído pelo DeCult. Haviam inaugurado quatro parques (Pedro II, Lapa, Ipiranga e o Santo Amaro) no primeiro ano, com metas de ampliar o projeto em mais 53 unidades, além dos campos de atletismo que seriam a continuidade correspondente dos parques, publicaram os estudos e os levantamentos estatísticos na Revista do Arquivo Municipal, no Congresso Nacional de Língua Cantada, na primeira, mensalmente as estatísticas e os levantamentos realizados pela Divisão de Documentação Histórica e Social, além da Sociedade de Etnografia e Folclore que servia de divulgação das ações culturais desenvolvidas pela prefeitura foi uma revista de ciências sociais, canais que serviram para promover os projetos e refletir sobre as consequências que esses estavam trazendo para os espaços onde eram desenvolvidos seus arredores e, é claro, a cidade. A referência internacional foi uma realidade, o DeCult recebia cartas e solicitações de acessória a projetos estrangeiros, como em Paris e Praga (DUARTE, 1975, p. 134) e convites para participações em congressos internacionais.

Esse sucesso só pode ser compreendido devido à doação e à seriedade pela qual os gestores públicos se envolveram na construção de uma ideia e de um discurso, que foi agradando aos poucos e convencendo a população paulista, embora a oposição política levantasse centenas críticas a respeito. O momento que viveu o DeCult foi importante por conta da aceleração e motivação de processos que não eram valorizados e colocados como prioridade na aplicação das políticas brasileiras. Como, por exemplo, a "loucura" e gastos exorbitantes com atividades banais, no momento investir em leitura, desenhos, gincanas e teatro para as crianças, eram tidos como lunáticos. Nota-se a partir das confirmações de Paulo Duarte e Mário de Andrade que ambos consideram os bairros populares desprovidos de qualquer integridade higiênica e educativa, impossibilitados de aspectos saudáveis e atrativos à vida infantil. "Os recintos fechados com estrutura" são oferecidos especialmente pela gestão pública, em um projeto piloto chamado Parque Infantil, que logo se multiplicará pela cidade de São Paulo dedicam esperança nos futuros resultados. Usaremos, neste momento, dos pensamentos de Canclini para analisar a gestão dos Parques Infantis, administradas pela Divisão de Educação e Recreio do DeCult:

\footnotetext{
"O mundo moderno não se faz apenas com aqueles que têm projetos modernizadores. Quando cientistas, tecnólogos e empresários buscam seus clientes, eles têm também que lidar com a resistência à modernidade. Não apenas pelo interesse em expandir o mercado, mas também para legitimar sua hegemonia, os modernizadores precisam persuadir seus destinatários de que - ao mesmo tempo que renovam a sociedade - prolongam tradições compartilhadas. Posto que pretendem abarcar todos os setores, os projetos modernos se apropriam dos bens históricos e das tradições populares." (CANCLINI, 2013, pp. 31)
}

Como já contextualizado anteriormente, o DeCult foi uma das consequências da Semana de 22, organizada pelos modernistas, que obviamente sofreram inúmeras e pesadas críticas às novas propostas que apresentaram no Teatro Municipal de São Paulo. Levaram suas propostas em forma de manifestos e de poemas, "odiaram" (ANDRADE, 1980) a forma com que as artes estavam sendo tratadas, elitizadas, europeizadas, dominadoras do fazer artístico, sem se aprimorar das manifestações brasileiras reais. A elite foi criticada e se doeu. Os considerados "modernizadores" foram aceitos e recebidos pelo grupo político, diretamente li- 
Artigos

gados ao então atual prefeito da cidade de São Paulo, conseguiram apoio necessário para realizar os sonhos projetos, que anteriormente não passavam de reuniões alcoólicas. "Em vários casos, o modernismo cultural, em vez de ser desnacionalizador, deu o impulso e o repertório de símbolos para a construção da identidade nacional." (CANCLINI, 2005, p.81). É o que acontece em São Paulo e no Brasil. Como representantes do poder público, os modernistas, teriam legitimidade para aplicar e ampliar os projetos. Da mesma forma que já apresentado anteriormente, os Parques Infantis, como projeto piloto da nova gestão se apropriaram dos bens históricos e das manifestações populares. De tempo em tempo, eram realizados eventos nos Parques Infantis, encontros, peças, exposições para apresentar aos pais, familiares e até mesmo aos políticos o que estava sendo produzido dentro dos parques. As manifestações populares que haviam sido mapeadas eram apresentadas no repertório de uma rica cultura mestiça e brasileira, compondo um cenário de vastas possibilidades inseridas ali naquele projeto, às margens da "pauliceia desvairada", aos parentes de trabalhadores e operários.

Examinamos mesmo que minimamente a influência modernista nas políticas culturais inauguradoras do Brasil, a partir de noções de Rubim e Canclini, o momento era único, onde o Brasil passava por uma transição sócio-político, recebendo imigrantes em uma fase de troca da gestão política, a política do café com leite caía diante da aristocracia liderada por Getúlio Vargas. São Paulo já demonstrava seus interesses opostos e o separatismo mesmo aderido pela população foi sufocado pelas forças nacionais em 1932. A ânsia de ter uma representação do país, do nacional, era clara entre os artistas do movimento de 22, entre eles, Mário de Andrade fazia suas pesquisas, levantamentos e coletas que seriam usados anos mais tarde como bagagem para as ações e a produção cultural e artística em uma instituição criada especialmente para modernizar a cidade de São Paulo. Dessas coletas, pesquisas, estudos e viagens estão inúmeras ações realizadas não só por Mário. As viagens antes mesmo da Semana de 22 com destino às Minas Gerais, que já havia sido apontada por Alceu Amoroso Lima e Rodrigo Melo Franco de Andrade, depois em 1924 com a caravana que erraria pelo interior do Estado, em 1927, 1928 e 1929, a viagem para a Amazônia até a Bolívia e o Peru, logo depois a viagem pelo Nordeste brasileiro serviram como repertório para completar as peraltices de Macunaíma. Nas viagens, coletou mais de 700 manifestações culturais brasileiras, o que permitiu refletir as inúmeras possibilidades da cultura brasileira, até então sem apresentar muitos destaques. Com novas potencialidades e um grande número de imigrantes chegando para o progresso de São Paulo, era fundamental abraçar todas as origens que transitavam.

Claramente, o que nos diz Canclini pode ser bem exemplificado neste processo da cidade de São Paulo: "O patrimônio cultural funciona como recurso para reproduzir a hegemonia dos que conseguem um acesso preferencial à produção e à distribuição dos bens."

Desta forma, o patrimônio cultural brasileiro (ainda não instituído judicialmente) e que passava por uma modelação, foi aos poucos sendo implantado na programação das atividades dos Parques Infantis distribuídos pela região periférica do município de São Paulo (1940)*, que contava com uma população de 1.325.261, com uma Taxa de Crescimento de 5,4, sendo que a população com mais de 10 anos de idade era de 1.059.399 pessoas, sendo 898.697 alfabetizados $^{6}$. A preocupação de Mário de Andrade e de outros intelectuais era buscar as raízes do povo. Independentemente de o espaço conhecer as produções e as manifestações populares, essas práticas entrariam pelo portão da frente nos Parques Infantis, ou seja, a formação da nacionalidade seria construída a partir de valores identificados anteriormente, na década de 1920 e 1930, pelos intelectuais, pelos modernistas. Mas o governo interpretava essa formação como uma maneira de centralizar o poder. Instigar o nacionalismo e os símbolos da nação, além da imagem de Getúlio Vargas como "salvador da pátria".

O que acontece no Brasil é justamente uma crise de identidade, um questionamento dentro da normalidade dos processos modernizadores, como afirma Hall: "As sociedades modernas são, portanto, por definição, sociedades de mudança constante, rápida e permanente.” (HALL, 2006, p.14). Enquanto no cenário europeu se questionavam sobre tudo até então produzido com grande peso da academia, no Brasil, a questão será referente à produção nacional dentro de uma essência brasileira. A identidade faz parte deste processo de mudanças e também evoca um elemento importante na análise das ações do DeCult.

\footnotetext{
* No ano de 1930, como havia sido instituído, não foi possível realizar o senso da população.

6 Prefeitura de São Paulo: http://smdu.prefeitura.sp.gov.br/historico_demografico/tabelas/pop_brasil.php
} 
Inserido como prática artístico/cultural dentro dos parques, instruídas as atividades que remetiam às práticas brasileiras com o peso do território e da investigação das diminuídas fronteiras que isso gerava. A questão central unicamente era encontrar e explorar os "Brasis" independentemente de seus respectivos espaços, diferentemente da posição centralizadora do governo de criar o Brasil a partir de uma identidade representadora e sólida. O DeCult buscava a imagem de Brasil reconhecendo e trazendo para perto da população o país do interior, de longe. Como o caso do coco, enriquecido pelas descirções de Mário de Andrade em uma de suas viagens (ANDRADE, 1987, p. 80).

O popular ganhava peso e espaço, legítimo, que seria desenvolvido ainda em espaços específicos, direcionados às crianças paulistanas que brincavam com o diferente e construiriam sua identidade a partir das inúmeras propostas de atividades que participavam, reconhecendo o distante e o próximo. Esta foi uma das práticas da gestão do governo da prefeitura de São Paulo, não muito duradoura, mas eficaz e evolutiva até meados de 1940. Com o Estado Novo, o DeCult, em 1940, já se resumia a uma única sala escondida. As ações foram se perdendo e a aceleração nos processos culturais e educacionais dentro das aplicações de políticas públicas foram esvaziadas e transferidas. O interesse pelo projeto do departamento foi sufocado e Mário fugiu envergonhado para o Rio de Janeiro. Acabadas as possibilidades no DeCult, os parques foram abandonados e envolvidos pelo capim, até serem exterminados de vez.

A contribuição nesta específica ação dos Parques Infantis, como exposta aqui, no antro de uma política pública cultural, foi um momento importante, de crescimento, mesmo com alguns erros, continua sendo um período fundamental pela qual pesquisadores se dedicam. ${ }^{7}$ Dessa forma usamos da contribuição de Ortiz: "Como as culturas entram em contato por meio dos homens, a base referencial deve ser uma agrupamento, uma coletividade de indivíduos que se desloca espacialmente. O choque ou a assimilação cultural se faz sempre no seio de um território, a nação, a cidade, o bairro.” (ORTIZ, 1997 p.75).

A absorção e a recepção das atividades das diferentes regiões e etnias brasileiras foram adaptadas à normalidade a partir dessas atividades diárias, das crianças mantendo contato com o diferente e o estranho. A referência das crianças era criada na relação familiar, no colégio e nos novos parques, que neles havia uma oportunidade de potencializar os novos ensinamentos.

Já contextualizamos o cenário brasileiro com alguns números da cidade de São Paulo. Os muros que rodeavam os parques não era somente uma divisória na separação maniqueísta que propôs Paulo Duarte, era também a aplicação de um empreendimento político, desenvolvido e gerido por intelectuais dominadores de saberes e práticas, principalmente acadêmicas, que impuseram, com o objetivo de disciplinar o povo paulistano, enquadrá-lo nas necessidades que surgiam. O conjunto de valores atribuídos na gestão do DeCult em um período que ainda não existia o termo "políticas culturais", foi administrado por intelectuais legitimados que criam em ampliando as visões e a capacidade de interlocução do cidadão morador da cidade, abriu caminhos para a diversidade cultural brasileira com inúmeras ações assumidas pelo órgão público. Essas ações se voltam a todas as classes e nacionalidades que ocupavam aquele território, vindas de inúmeros lugares do mundo, encontrando na capital econômica brasileira novas práticas e costumes. A cultura vista passa a ser tratada como essência e, inserida em um contexto de baixos números relativos a produção e consumo cultural, além é claro da educação básica que foi estruturada nos parques, antes mesmo dos projetos de Anísio Teixeira e Darcy Ribeiro.

\section{Bibliografia}

APOSTOLIDES, Jean Marie. Rei Máquina: o espetáculo e política no tempo de Luís XIV. Brasília, Edu$\mathrm{UNB}, 1993$.

ALVARENGA, Oneyda. Mário de Andrade, um pouco. Rio de Janeiro, J. Olympio; São Paulo, Conselho Estadual de Cultural, 1974.

ANDRADE, Mário. Macunaima. O Herói sem nenhum caráter. 16 ed. São Paulo, Martins Fontes, 1978.

7 Alexandre Barbalho, Antonio Ruim, Lia Calabre, Maria Lourdes da Fonseca, Mario Chagas, entre outros 
Padre Jesuino do Monte Carmelo. Rio de Janeiro, Nova Fronteira, 2012.

Paulicéia Desvairada in: Poesias Completas. 8 ed. São Paulo, Martins Fontes, 1980.

O Turista Aprendiz. São Paulo, Duas Cidades, Secretaria da Cultura, Secretaria de Ciência e Tecnologia, 1976.

Pequena História sobre a música brasileira. Belo Horizonte, Itatiaia, 1987.

BARBALHO, Alexandre. Politicas Culturais no Brasil. Salvador, EUFBA, 2007.

CASTRO, Moacyr Werneck. Mário de Andrade, exílio no Rio. Rio de Janeiro, Rocco, 1989

CANCLINI, Nestor Garcia. Culturas Híbridas. 5ed. São Paulo, EDUSP, 2013.

CUNHA, Euclides da. Caderneta de campo. Introd., notas e comentário por Olímpio de Souza Andrade. São Paulo, Cultrix; Brasília, INL, 1975

DUARTE, Paulo. Mário de Andrade por ele mesmo. 2.ed. São Paulo, Secretaria Municipal de Cultural, 1985.

HALL, Stuart. A identidade cultura na pós-modernidade. Rio de Janeiro, 2001.

HOBSBAWM, Eric. A Era dos Extremos. São Paulo, Cia das Letras, 1999.

Mário de Andrade e os Parques Infantis. (in) Revista Itaú Cultural. São Paulo, Itaú Cultural, 2013.

SANDRONI, Carlos. Mário contra Macunaima: cultura e política em Mário de Andrade. Rio de Janeiro, IUPRJ, 1988.

ORTIZ, Renato. Mundialização da cultura. São Paulo, 1997.

PREFEITURA DA CIDADE DE SÃO PAULO. Instituto Histórico e Geográfico da cidade de São Paulo. Tabela de Estudos Demográficos. Apresenta levantamentos referentes ao senso de 1940 na cidade de São Paulo. Disponível em: <http://www.smdu.prefeitura.sp.gov.br/hitorico_demografico/tabela/ pop_brasil.php>.Acesso em: 19 ago. 2014.

WAINER, J. P. A mundialização da cultura. Bauru: Editora da Universidade Sagrado Coração, 2000. 